\title{
Future Vision at Industrial Design \& Disappearing Objects
}

abstract With the increasing rate of change, using today's data in decision making processes is seen as insufficient by futurists. To keep pace with the change, having a future vision is an up-to-date topic. Thus in social, economical and political areas futurists are making studies to be ready to future.

At Industrial Design profession the importance of future vision is began to be noticed as well. Designers are researching on usage of futures research methods within design methods. Normative methods are seen as compatible with design process.

Analyzing future and study of foresighting it focuses on products and environments for designers. Marzano (2002) forecasts that todays technologies will disappear and timeless objects will remain in the future. G.Q. Maguire Jr. (1998) uses "disappearing object" definition in his study and makes a list of possible disappearing objects of the future. With analyzing of "disappearance" concept, future vision at industrial design can be formed. In order to analyze this hypothesis, "Disappearing Object-Radio Concept at 2020" workshop was carried out by using qualitative and future research methods.

industrial design, future research methods, futurism, disappearing objects

\section{Introduction}

Technological developments and the pace of change in the twentieth century have changed the society and its perception (Toffler, 1981). Analyzing today's needs and demands is insufficient to be abreast with the times. Thence, futures studies are made in areas such as economics, sociology and politics to keep up with change or to achieve the desired change.

Design profession has also been influenced by the rapid changes. Artifacts', Usability, needs and meanings of artifacts changes or new artifacts arise with the use of new technologies. In this study, the role of future vision in Industrial Design will be examined and within the "Disappearing Object-Radio Concept at 2020" design exercise, disappearance concept will be used to create future oriented scenarios.

\section{Futures Studies \& Industrial Design}

The change rate upon time and designers need to move with the time emphasized the importance of futures research and future research methods at design studies.

One of the first instances can be seen at 1939 New York World's Fair, Futurama Exhibit designed by Norman Bel Geddes, depicting a possible model of the world 20 years into the future (1959-1960).

During the 1960 s radical utopia period, groups like Archigram, Superstudio, and Archizoom set up their own utopias. Designer Luigi Colani designed his utopia YLEM, as well. He 
theme 4

technology

Figure 1.

Futurama Exhibit (URL-1)

Figure 2.

Futurama Exhibit (Bangert, 2005). strand 1

history of technology: traditions, transitions and trajectories
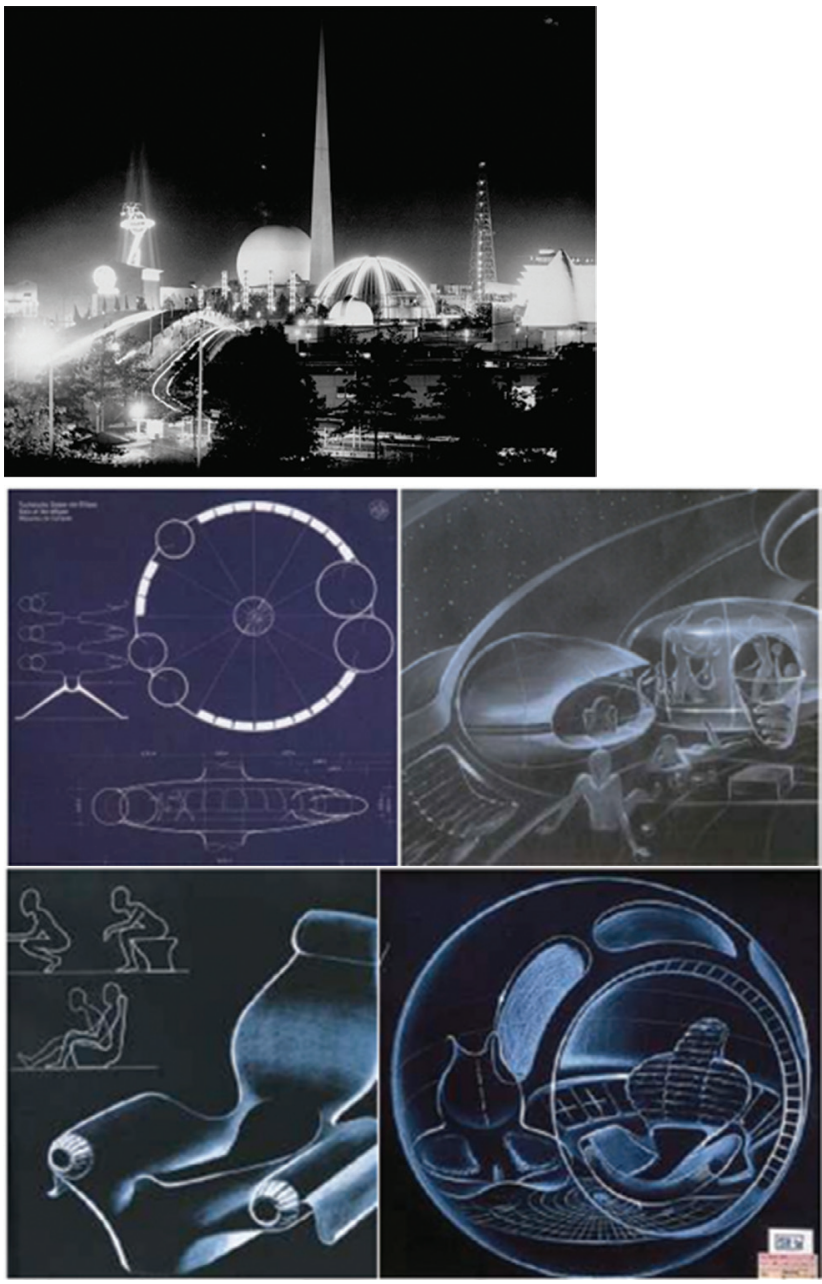

indicates that designers' independent attitude defines them as "intellectual time shapers" instead of technocrats (Bangert, 2005).

Futures also began to be handled at thesis projects and courses have been given at universities and seminars have been organized. (10 to 11 December 2002, Future Perfect Conference held in Brussels, 18 February 2003 National Design and Foresight Seminars held in London, 21 February 2003, held in Helsinki Design and Creativity in Futures Foresight)(DFFN, 2003).

Futures also began to be handled at thesis projects and courses have been given at universities and seminars have been organized. (10 to 11 December 2002, Future Perfect Conference held in Brussels, 18 February 2003 National Design and Foresight Seminars held in London, 21 February 2003, held in Helsinki Design and Creativity in 
Futures Foresight)(DFFN, 2003).Studying on the future is called as "Futures Studies"; because there is not one possible future, there are lots of alternatives. Designer Evans \& Sommerville says, futures' thinking - the systematic study of the future - provides design with a structured approach to consider potential futures (Evans \& Sommerville, 2007).

Jensen (2005), instructor at the Department of Product Design at the Norwegian University of Science and Technology concurs that "trend forecasting and future research methodologies should be a subject in the industrial design education program".

Ratner (2007) suggests that, if product designers need to be more visionary, in order for them to contribute products that support a future we want to live in, then educators need to rethink pedagogy and design curriculum to better develop this competency.Besides theoretical studies on Futures Studies and Industrial Design relationship, many companies are developing future perspectives as part of their decision making process.

Siemens publishes Pictures of the Future, in part to advertise their development of new technology. It is not really focused on design (URL-2). Philips Design is trying to forecast the future with projects like Delphi or Vision of the Future. (URL-3)

Shell has done extensive studies to forecast the future with the goal of assessing the future of fuel. They have published some of the results and are trying to diversify their business strategy due to the upcoming scarcity of oil. (URL-4) (Rodriguez et al, 2005).

\section{Disappearing Objects}

"The telephone industry has gone from the dial phone, to the push button phone, to the cordless phone, to the cell phone, to the .... Eventually the cell phone device will disappear. We do not need to be able to see technology to interact with it."

Thomas Frey, Da Vinci Institute (URL-5)

In Futures Studies we come across with a new concept: Disappearance. G.Q. Maguire Jr. (1998) uses "disappearing object" definition in his study and makes a list of possible disappearing objects of the future (Table 2).

Marzano (2002) says that the home of tomorrow will look more like the home of yesterday than the home of today. The bulky boxes containing today's ageing technologies will "disappear", and the function we need will be hidden in timeless objects such as furniture, containers, ornaments, walls, floors, and roofs.

Marzano or Maguire do not indicate disappearance as being non-exist; but transforming in shape, meaning or affordance.Futures Studies has a dialectic function for designers:

\begin{tabular}{|c|c|}
\hline Wired phones & garage door openers \\
\hline Condless phones & wireless car doortvehicle security transmitters \\
\hline Mobile (cellular) phones & GPS units (as a separate single purpose device) \\
\hline (pocket) radios [Also applies to vehicles] & calculators \\
\hline stereo receivers & $\begin{array}{l}\text { erodit cardv/checksveash (the later will soon be } \\
\text { outlawed in any case) }\end{array}$ \\
\hline tape decks & clocks and watches \\
\hline TVs & pagers \\
\hline $\mathrm{CD}$ playens & $\begin{array}{l}\text { computers as PCs Workstations... f which we } \\
\text { already can not always recognize!) }\end{array}$ \\
\hline modems & File Cabinets" \\
\hline answering machines & ATM machines \\
\hline cable decoders & Maps \\
\hline FAX machines & Thermometers \\
\hline newspapers and other periodicals (in print form) & Business Cards \\
\hline film based cameras (except for pure bobbyists) & Security Badges \\
\hline vCRs and camcorders & Toll Booths \\
\hline
\end{tabular}

Table 2.

List of products which will disappear (G.Q. Maguire Jr., 1998) 
theme 4

technology

strand 1

history of technology: traditions, transitions and trajectories

inspiring from the future and/or designing the future. Disappearance concept can be regarded as a trend to study on at future oriented design exercises.

For decades, radio has played an important role on society as the source of information and entertainment; so to analyze the efficiency of disappearance concept usage, radio has been chosen as the subject of study.

\section{The Study of "Disappearing Object-Radio Concept at 2020"}

\subsection{Transition of Radio}

Radio was invented at the beginning of zoth century. The inventor was not a single person. The idea of the radio grew out of the work of many people (Waorland, 2004). Guglielmo Marconi can be called as the father of radio. In 1901 Marconi sent signal with his radio from England to Canada. After that Marconi and his radio became famous (Waorland, 2004).

In these decades radio had a vital role on people. Radio was the only source for people to get the latest newsThey could get the latest news, listen to music and be aware of the world only from radio. Advertisements from these times show the importance of radio (Figure 1).

In time radio has changed its function and form with the arise of new technologies. In 21th century we do not see radio as a physical object so much. Todays interactive online web sites are called as radio as well, in which user can arrange their playlist as they will. But while using these web sites do users really think that whether this is a radio? It can only be seen as an internet site by the user. The important question is did people really forget the radio or not. Edward and Dennis (1994) defines radio as "the forgotten medium" in their books. These circumstances make radio a relevant candidate for a "disappearing object". In this study with the "disappearing object" framework, disappearance type of radio object will be analyzed also by using futures research methods future scenarios will tried to be composed.

Figure 3.

Figure 3. Future radio forecast (URL-6)

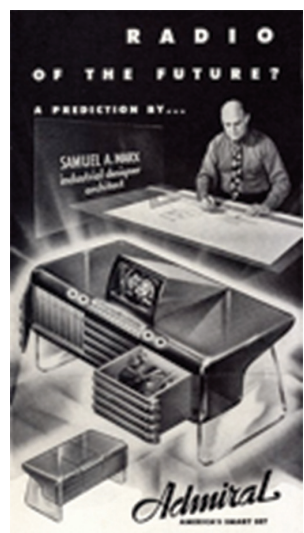

\subsection{Method}

"Disappearing Object-Radio Concept at 2020" study was performed under two main headings. At the beginning a questionnaire was made to understand the radio concept at people's perception, how people define and what do they want from the radio. Data, obtained from questionnaire study, analyzed and used as information at the second stage of this study. 
The second stage of the study is composed of a workshop. The topic of workshop was "Radio Concept at 2020". Participants were chosen among the second and third year Industrial Design students. Data obtained from questionnaire study was used as main information at brainstorming session. Scenarios and sketches requested from all participants and at the end of workshop all studies analyzed together.

\subsection{Questionnaire}

Questionnaire was composed of both qualitative and quantitative approached 19 questions. 50 people participated in the survey from different age group (Table 3).

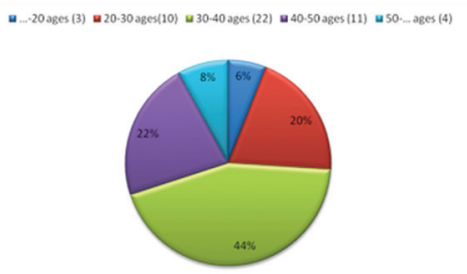

Table 3. Age Graph of Participants

Table 4. Type of radio usage
The definition of radio asked to from participants and most of the results were emotional as: "A friend", "A harmless way of communication", "The way from ear to mind and to hearth", "The world which I do not see but hear", "News and fun source for me", "joyfull", "It is a friend while making homework" 46 radio using participant asked to explain what type of radio they use.

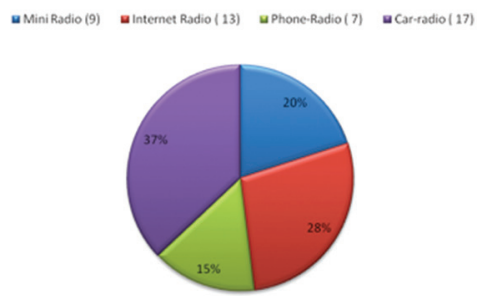

To obtain internet radio usage rate, asked to participants asked whether they use internet radio or not. As a result 28 people said yes, 9 people said no and 13 people said sometimes. Participants asked whether they consider interactive music sites like Musicovery, Grooveshark and Fizy as a radio and 16 people said yes, 20 people said no and 14 people had no idea about the internet sites.

In the second part of questionnaire rating scale used to analyze the type of radio usage and needs.

The results of the questionnaire show that people still use radio; but the perception of radio differs. Usage of the phone radios and car radios are popular than the interactive or internet radios. \% 44 of participants think that radio does not have to be in a physical form. The only purpose of the radio is not to listen music. Getting information from news or listening a song that you do not know is important.

\section{4 "Radio Concept at 2020" Workshop}

With total 10 participants from 2. year and 3. year Doğuș University Industrial Design students, "Radio Concept at 2020" Workshop was made. It organized in 3 section. In the first section workshop topic demonstrated and future forecasting methods explained to participants. This section managed by workshop leader and processed as monolog ( Duration:15 minutes) 
theme 4

technology strand 1

history of technology: traditions, transitions and trajectories
In the second section brainstorming study was made. Data obtained from questionnaire study was shared with participants and thoughts organized about future events and trends. Participants made interpretations one by one with short sentences at disorderly. In the third section participants asked to write scenario or/and make sketches about the the radio concept at 2020 .

\subsection{Results}

During the first stage of workshop futures research methods were demonstrated to participants, noticed that, participants were mostly using normative methods. Yet some of the participants firstly used exploratory methods and then used normative methods on them to make scenario more optimistic.

Participants' foresights mainly focused on: the age of the society will rise, people will work more and they will be more lonely. With contaminating the nature they will be old but not healthy. In the dissenting opinion they will be more educated and aware of their environment. As physical form all of them thought radio as small objects like chips which can be mounted on clothes or environment. As meaning all of them designed the radio as a communication device which gives the user confident and social character.

One of the participants designed radio as a communication and a healer object. Which arranges your mood by sending signals to your body. And again with signals people can find somebody else who is in the same mood. It gives the user a chance to be social and heals user.

Another participant put the radio behind the walls. User can have a control device and can regulate the radio when to start and stop. It starts to play as user enters to home and analyses users mood and changes the channel accordingly. It designed to make lonely people happy.

\section{Conclusion}

Figure 4. Sketch from workshop

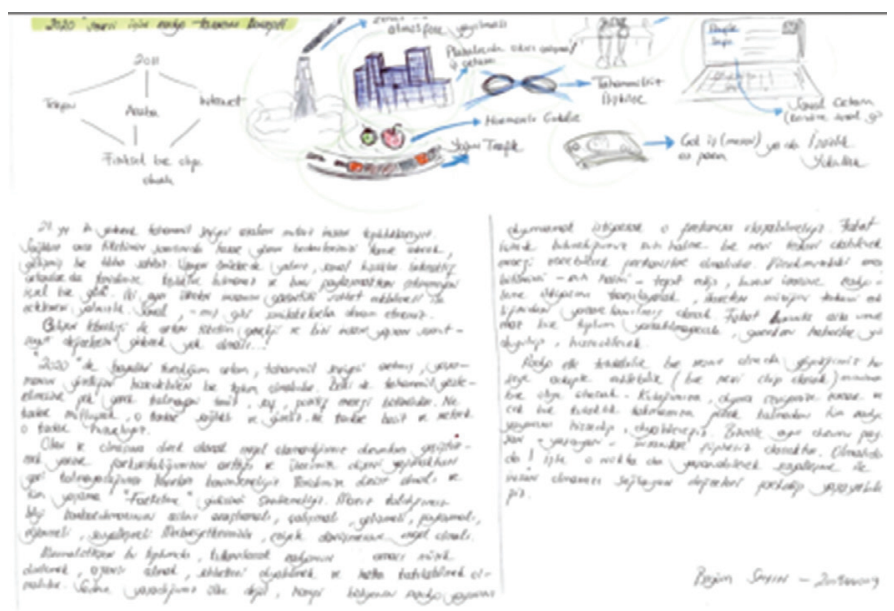


The main subject of the study is Futures Studies and the contribution of Futures Research Methods at Industrial Design. Under this heading "Disappearing object" concept analyzed and chosen as the study topic. Concept defines that objects change by the time according to technology, needs, society, conditions ... etc; while some of items dies totally, some of them changes its form and transfers their meaning to it yet some of them change its meaning totally. These changes can be analyzed and with futures research methods can be transformed to futures products or today's products for directing the future. In order to test this point of view "Disappearing Object-Radio Concept at 2020" workshop was done. With the usage of methods participants began to think about the meaning of object and established relationships with object and environment. Embedding this future vision in Industrial Design Education can extend students approach to design process, analyzing the dynamics of changing society and meaning transformation of artifacts

\section{References}

Bangert, A. (2005) Colani: Tha Art of Shaping the Future.

DFFN. (2003) Design for Future Needs, EC Report Contract No. HPV1-CT-2001-60038. Evans, M. and Sommerville, S. (2007) Design Led Futures: Futures Thinking in the Design Curriculum, Connected 2007: International Conference On Design Education, University Of New South Wales, Sydney, Australia.

Edward C. Pease and Everette E. Dennis. (1994) Radio-The Forgotten Medium, Transaction Publishers, United States of America.

Gerald Q. Maguire Jr. (1998) Personal Computing and Communication, Webnetg8,

Orlando, Florida, USA.

Glenn, Jerome C. (1994) Introduction to the Futures Research Methodology Series, United Nations University's Millenium Project Feasibility Study.

Jensen, C. Future Forecasts in Product Design: Guidelines to predicting the future. Designing Products for the Future, available at: http://www.ivt.ntnu.no/ipd/fag/ PDg/2005/artikler/PDgartikkel_carmilla_Jensen.pdf, accessed at 10.03.2013. Marzano, S. (2002) Ambient Intelligence in HomeLab, Royal Philips Electronics. Rodríguez, E., Fraser, S. and Stevens, R. (2005) Future Scenarios and Product Design: A Contextual Model, MX Design Conference 2005: Design Perspectives - Envisioning design for the XXI century, University Iberoamericana, Mexico.

Ratner, E. (2007) Teaching Visionary Thinking to Product Designers Using Lessons from Utopian Science Fiction, EPDE Conference.

Waorland, G. (2004) The Radio, Great Inventions, Capstone Press, United States of America. Toffler, A. (1981) Gelecek Korkusu, Altın Kitaplar Yayınevi, İstanbul.

URL-1. Retrieved March 21, 2014, from http://wwwwired.com/2010/O4/gallery-1939-worlds-fair/all/

URL-2. Retrieved March 10, 2013, from http://www.siemens.com/pof

URL-3. Retrieved March 10, 2013, from http://www.design.philips.com

URL-4. Retrieved March 10, 2013, from http://www.shell.com

URL-5. Retrieved October, 2013, from http://www.davinciinstitute.com/papers/the-future-of-libraries/

URL-6. Retrieved November 5, 2013, from http://andrewraimist.com/2010/og/marxs-

radio-of future-circa-1942.html 
